$0.10, \mathrm{p}<0.04)$ and waist circumference $(\mathrm{b}=-0.24, \mathrm{p}<0.001)$ were negative.

Conclusion Dietary patterns of adults with diabetes were found to be associated with biochemical profiles. Mixed dietary pattern include nuts, fruit, olive oil and tea could improve lipid profiles. Further studies are necessary to confirm the benefits of the mixed pattern and develop practical dietary guide-line for diabetes.

\section{PO-0058 BIOIMPEDANCE ANALYSIS IN CHILDREN AGED 0-14 YEARS: IS THERE A RELATION BETWEEN PHASE ANGLE AND WEIGHT AND BODY SURFACE AREA?}

${ }^{1} \underline{S}$ Brantlov, ${ }^{2} \mathrm{~L}$ Jødal, ${ }^{3} \mathrm{~A}$ Lange. ${ }^{1}$ Department of Clinical Engineering, Aarhus University Hospital, Aarhus, Denmark; ${ }^{2}$ Department of Nuclear Medicine, Aalborg University Hospital, Aalborg, Denmark; ${ }^{3}$ Department of Paediatrics, Aarhus University Hospital, Aarhus, Denmark

\subsection{6/archdischild-2014-307384.731}

Background and aim Knowledge of fluid compartment changes and nutritional status is crucial when evaluating critically ill children, as well as measuring the effect of treatment.

Current reference methods (DXA, dilution-methods etc.) are invasive, expensive, and/or time consuming and are therefore not suitable for routine paediatric examination.

Bioimpedance analysis (BIA) offers an alternative to this since it is non-invasive, simple, portable and inexpensive.

One BIA approach is to use values of total body fluid (TBF), extra- and intracellular fluid (ECF, ICF) and/or body cell mass (BCM). These are based on predictive equations and only proven in adults. Another approach is to use the phase angle (PA), which is a combination between the electrical resistance $(R)$ of the electrolytic-containing TBF, and the capacitive reactance $\left(\mathrm{X}_{\mathrm{C}}\right)$ of the cell membrane, both expressed in ohms $(\Omega)$. PA is an indicator of fluid compartment changes and cell membrane properties.

Aim To investigate the relation between PA and weight $(\mathrm{kg})$ and the body surface area, BSA $\left(\mathrm{m}^{2}\right)$.

Methods Whole-body BIA was performed in 47 healthy children (boys $=33$, girls $=14,0-14 \mathrm{yr}$ ). PA ( $\arctan =\mathrm{X}_{\mathrm{C}} / \mathrm{R}$, degrees) was measured at $50-\mathrm{kHz}$ with a bioimpedance spectroscopy device (Xitron 4200). Statistics: Spearman's rank correlation (r), p < 0.05 and a $95 \%$ confidence interval.

Results Data showed high positive correlations between PA and weight and BSA (Table and Figure).

Conclusions PA offers promising perspectives for further research areas (e.g. gender influence on PA). Potentially, PA could be a new way of monitoring fluid compartment changes and nutritional status in critically ill children.

Abstract P0-0058 Table 1 Correlation data of boys and girls combined

\begin{tabular}{|l|c|c|c|}
\hline Parameters & $\boldsymbol{r}$ & P-value & $95 \% \mathrm{Cl}$ \\
\hline PA (degrees) vs. weight $(\mathrm{kg})$ & 0.74 & $P<0.0001$ & 0.58 to 0.85 \\
\hline PA (degrees) vs. BSA $\left(\mathrm{m}^{2}\right)$ & 0.75 & $P<0.0001$ & 0.59 to 0.85 \\
\hline
\end{tabular}

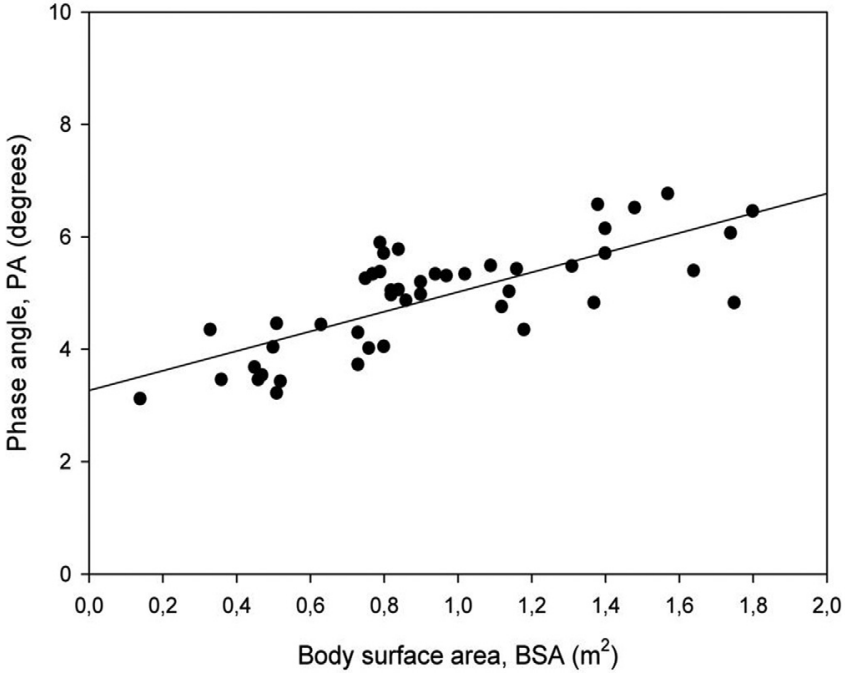

Abstract P0-0058 Figure 1 Relation data of boys and girls combined

\section{PO-0059 CENTRAL DIABETES INSIPIDUS IN CHILDREN: CLINICAL PROFILE AND ETIOLOGIES MONOCENTRIC EXPERIENCE (ABOUT 10 CASES)}

M Tfifha, N Missaoui, S Mabrouk, H Ajmi, J Chemli, N Zouari, S Hassayoun, S Abroug. Pediatrics, University Hospital Sahloul, Sousse, Tunisia

\subsection{6/archdischild-2014-307384.732}

Introduction Central diabetes insipidus (CDI) or neurohypophyseal diabetes insipidus is a rare disorder in children caused by an inadequate release of the antidiuretic hormone, arginine vasopressin (AVP). CDI is clinically caracterised by polyuria and polydipsia.

Methods and materials Clinical, auxological, biological and neuroradiological characteristics of 10 children with central diabetes insipidus (CDI) were retrospectively analysed during a period of 18 years.

Results Five girls and five boys with permanent diabetes insipidus were enrolled in the study. The mean age at diagnosis was 6 years five months (range: 4 months -14 years). The major cumulative and often subtle presenting manifestations were: polyuria $(n=10)$, polydipsia $(n=10)$, fatigue $(n=2)$, growth retardation $(n=4)$, headache $(n=1)$. All patients had low urine osmolality and elevated plasma osmolality on diagnosis.

The aetiology of central DI was organic in 8 patients, craniopharyngioma in 3 patients, Langerhans cell histiocytosis in 2 patients, neurosarcoidosis in one case, Pituitary stalk interruption in one patient and wolfram syndrome in one patient.

Three patients had anterior pituitary hormone deficiency and growth hormone deficiency.

Polyuria and polydipsia have regressed in all patients put under desmopressin. Patients with craniopharyngioma were operated with a tumour recurrence in one case.

Conclusion DIC is a rare disease in Paediatrics. The circumstances of discovery and positive diagnosis are often easy. The underlying aetiology of CDI in children may not initially be obvious. Long-term surveillance is therefore necessary, especially for the early detection of evolving treatable intracranial lesions. 